\title{
De grupo de presión a actor político: infraestructuras de paz y madurez del conflicto en Colombia ${ }^{i}$ From Pressure Group to Political Actor: Peace Infrastructures and Maturity of the Conflict in Colombia.
}

\section{Por: Javier Alexander Molina Correa' \& Sergio Vargas Velázquez²}

\footnotetext{
1. Profesional en Estudios Políticos y Resolución de Conflictos. Maestro en Ciencias Sociales de la Universidad Autónoma del Estado de Morelos, México. Profesor del Ministerio de Defensa Nacional de Colombia. Orcid: https://orcid.org/0000-0002-9538-1947 Scholar: https://scholar.google.com/citations?user=k-atTpEAAAA]\&hl=es Contacto: javieralexandermolina@outlook.com

2. Economista y Sociólogo. Doctor en Antropología Social de la Universidad Iberoamericana. Profesor Investigador de la Universidad Autónoma del Estado de Morelos, México. Orcid: http://orcid.org/0000-0001-7169-0844 Scholar: https://scholar.google.com/citations?user=DL1XCGMAAAA]\&hl=en Contacto: sergio.vargasvme@uaem. edu.mx
}

OPEN ACCESS

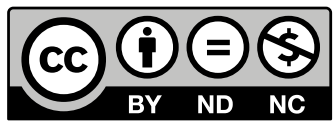

Copyright: $\odot 2020$ El Ágora USB

La Revista El Ágora USB proporciona acceso abierto a

todos sus contenidos bajo los términos de la licencia

creative commons Atribución-NoComercial-SinDeri-

var 4.o Internacional (CC BY-NC-ND 4.0)

Tipo de artículo: Investigación

Recibido: noviembre de 2019

Revisado: diciembre de 2019

Aceptado: febrero de 2020

Doi: $10.21500 / 16578031.4444$

Citar así: Molina Correa, J.A. \& Vargas Velásquez, S. (2020). De grupo de presión a actor político:

infraestructuras de paz y madurez del conflicto

en Colombia. El Ágora USB, 20(1). 37-56.

Doi: $10.21500 / 16578031.4444$

\section{Resumen}

Las infraestructuras de paz, desde su génesis en la administración de Belisario Betancur, en Colombia, han sido grupos de presión de carácter privado y mixto en menor medida, que están en una constante lucha por constituirse como un actor político con un grado mayor de institucionalización, valiéndose de la movilización social de manera pacífica. Estos grupos de presión a diferencia de los partidos, solo pretenden influir el sistema político. Se concluye que las infraestructuras de paz, han transitado de ser un grupo de presión a un actor político con participación directa y necesidades puntuales en el posconflicto.

Palabras clave: Grupo de presión; infraestructuras de paz; negociaciones de paz; madurez del conflicto; víctimas.

\section{Abstract}

Peace infrastructure, from its onset under Belisario Betancur's term, in Colombia, has been pressure groups of a private and mixed nature to a lesser extent, which are in a constant struggle to establish themselves as a political actor with a greater degree of institutionalization, by using social mobilization peacefully. These groups of pressure, unlike parties, are only intended to influence the political system. It is concluded that peace infrastructure has gone from being a pressure group to a political actor with direct participation and timely needs in the post-conflict.

Keywords: Pressure Group; Peace Infrastructure; Peace Negotiations; Maturity of the Conflict; and Victims. 


\section{Introducción}

Este trabajo busca realizar un ejercicio exploratorio que permita indagar sobre las condiciones que incentivaron la madurez del conflicto desde una perspectiva relacional, con el concepto de infraestructuras de paz. Se analiza la participación de organizaciones propias de la sociedad civil en el incentivo a las negociaciones de paz en Colombia. Se utilizan como referentes teóricos los conceptos de "Appropriate Timing" (madurez del conflicto) de Christopher Mitchell e "Infraestructura de paz" de Jean Paul Lederach. Metodológicamente, se realiza un análisis documental en el cual se determina el nivel de influencia para la paz, de las organizaciones civiles desde los años ochenta hasta la actualidad. Se concluye que las infraestructuras de paz, han transitado de ser un grupo de presión a un actor político con participación directa y necesidades puntuales en el posconflicto.

El 24 de noviembre del año 2016, fue uno de los días más importantes para Colombia en su historia. En dicha fecha, se logró llegar a la firma de un acuerdo de paz entre las FARC-EP y el gobierno de Juan Manuel Santos Calderón. Este acontecimiento no solo marcaría el fin del accionar de la guerrilla más añeja de América Latina, sino que también permitió dilucidar un nuevo derrotero para transitar de la guerra a un escenario de posacuerdo.

Sin duda, la relevancia de lo relatado, no es más que un fuerte insumo empírico que reforzará la vasta literatura analítica sobre conflicto armado e investigación para la paz en Colombia. Este trabajo pretende configurarse como un producto articulado a la segunda línea mencionada. Si bien sobre negociaciones y construcción de paz en Colombia se viene escribiendo desde el año 1995, con un texto que sirvió como génesis redactado por Jesús Antonio Bejarano denominado Una agenda para la paz: aproximaciones desde la teoría de resolución de conflictos (Valencia, 2017); lo reciente de la firma del acuerdo de paz lo convierte en un área de oportunidad académica dispuesta a recibir constantes contribuciones.

En este trabajo pretendemos aterrizar la mirada hacia el asunto nominado, haciendo hincapié en la capacidad de influencia de la sociedad civil como tercer actor directamente inmerso en el conflicto armado, social y político colombiano para lograr la firma de un acuerdo de paz en la negociación de Juan Manuel Santos Calderón y la guerrilla de las FARC-EP, después de tres intentos frustrados en administraciones anteriores: la de Belisario Betancur (1982-1966); César Caviria (1990-1991) y Andrés Pastrana (1998-2002). También se nombrarán algunos sucesos importantes en otras administraciones dentro de la temporalidad delimitada. En este orden de ideas, más que determinar las razones desde un enfoque puramente racionalista por las cuales los actores directamente en conflicto (gobierno e insurgencia) decidieron firmar la paz, lo que se busca es explorar las acciones ejecutadas por agentes no estatales y el rol que estos decidieron ocupar en la secuencia histórica delimitada desde la primera hasta la última negociación, con el fin de influir y conducir al fin de la manifestación bélica del conflicto.

Así pues, es necesario tener claridad sobre las tres coordenadas teórico-conceptuales que orientan el análisis, en el marco de la investigación para la paz contemporánea. Estas son: la coordenada epistemológica, la coordenada teórica y la coordenada conceptual. La primera, será la propuesta epistemológica del profesor Francisco Muñoz (2011) de la Universidad de Granada (España) con su concepto de paz imperfecta, comprendida como la satisfacción de necesidades, desarrollo de capacidades o lugares donde se gestiona la regulación pacífica de los conflictos. Para este autor, la paz es imperfecta, porque pueden ser acciones muy pequeñas o muy grandes, puede incluir el aspecto personal, domestico, local o internacional. Lo más interesante es que, desde su perspectiva, se puede convivir y construir con el conflicto y la violencia misma. Para él, es importante detectarla porque se puede mejorar, potenciar o expandir. Se relegará parcialmente el concepto de paz negativa propia del enfoque violentológico hegemónico que va de la temporalidad enmarcada de 1930 a 1959 y la paz positiva desarrollada hasta finales de los años 90 del siglo pasado. 
Es válido aclarar que los estudios relacionados con la construcción de paz, nacen con la intención de buscar la ausencia de guerra, que no es más que la manifestación violenta del conflicto político. Es por esta razón que los estudios de paz en los casi 30 años que van de 1930 a 1959, se enfocaron en la paz negativa (ausencia de violencia directa) y los conflictos entre Estados desde las relaciones internacionales. En adelante, la paz positiva será la concepción dominante de la mano del planteamiento de Johan Galtung (1998) de la paz vista como ausencia de violencia directa, estructural y cultural. Los estudios de la época se enfocarán en el desarrollo y la justicia como pilares de paz. Sin embargo, en el siglo XXx el paradigma de paz será cambiado por el concepto de paz imperfecta dadas las dificultades empíricas de estudiar la paz bajo una propuesta de paz positiva, puesto que es muy difícil que un mismo escenario se conciba la ausencia de los tres tipos de violencia. Nacen también como subtemas de estudio la cultura de paz y la educación y comunicación para la paz (López, 2011).

Por su parte, Grasa y Mateos (2011) hacen un importante aporte a la segunda coordenada, la teórica. Ellos plantean que para estudiar temáticas afines a la construcción de paz, es oportuno segregarla por etapas o fases. La primera es la preparación para la paz, es decir el vínculo entre lo que fue el conflicto y la negociación. Ceneralmente se exploran las causales que condicionaron el cambio de perspectiva en la racionalidad de los actores, pasando de la guerra, a la consideración de la paz como una salida real del conflicto.

La segunda fase, son las negociaciones en sentido estricto, $y$ todos los aspectos ligados a la mediación; la violencia (y su presencia en cualquier etapa del proceso); la tercera son los acuerdos alcanzados, la cuarta es la implementación y finalmente, el postconflicto-consolidación de la paz. Se considera oportuna la distinción entre el concepto de construcción de paz y la de consolidación de la paz, la primera es definida por Grasa y Mateos (2011, p.18) como una "Serie amplia de actividades concretas y multidimensionales capaces de permitir restaurar o instaurar relaciones sociales y políticas entre personas y grupos con el fin de evitar el recurso a la violencia". Por su parte la consolidación de la paz es entendida como

Actividades realizadas a partir de la terminación del conflicto armado (es decir, la firma de un acuerdo de paz definitivo) con el objetivo de incentivar la recuperación del país después del conflicto. Su ámbito de labor se compone de acciones humanitarias, políticas, de seguridad y de desarrollo" (Galaviz, 2013, p.51).

Este trabajo se ajusta a la primera y segunda fase, puesto que pretende explorar la presencia y roles desarrollados por infraestructuras de paz en esa constante búsqueda del fin del conflicto a través de la negociación en las tres administraciones que no lograron llegar a la firma de un acuerdo; la negociación en la administración Santos que si lo logró; y su presencia una vez finalizadas las conversaciones.

La coordenada conceptual por su parte, será la ya mencionada, infraestructuras de paz, esta se configura a través de la siguiente noción:

Para terminar un conflicto de manera no-militar y construir una paz duradera no basta sólo con tener buenas voluntades o un proceso de negociación entre los actores armados (aquellos directamente inmersos en el conflicto), se necesitan espacios permanentes dotados de legitimidad, autoridad y recursos con los cuales los diferentes actores de la sociedad, incluyendo las partes del conflicto, preparan la paz y la sostienen en el tiempo" (Pfeiffer, 2014, p.4).

\section{Metodología}

La pregunta de investigación que orientará el análisis será la siguiente: ¿Cómo ha sido el proceso de influencia y participación de las infraestructuras de paz en el marco de las negociaciones entre las FARC-EP 
y el gobierno de Colombia del año 1982 al 2018? La hipótesis que sirvió como respuesta tentativa durante la elaboración del escrito y que se plasmará en la conclusión del artículo, es que en el transcurso de la secuencia histórica señalada, las infraestructuras de paz tuvieron tres momentos en su etapa de influencia: la primera, fue la de apoyo a los procesos de paz emprendidos y hasta cierto punto la configuración de nuevos grupos de presión en aras del estímulo del fin del conflicto (1982-2002); la de participantes en la negociación (2012-2016) con las comisiones de víctimas que viajaron a La Habana, colaborando en el proceso de mediación para que las partes en conversaciones se mantuvieran en la mesa y la de legitimadores de lo firmado (2016 en adelante), manifestándose principalmente desde el ámbito electoral y local.

Es necesario desde este punto, traer insumos de la discusión epistemológica. Della Porta y Keating (2008), definen dos grandes paradigmas para hacer investigación en estas disciplinas: el positivista y el interpretativo. El primero, tiene una fuerte tendencia a emular el método de trabajo de las ciencias naturales y exactas, es decir, su objetivo intrínseco es la búsqueda de leyes o teorías de gran alcance. Por otro lado, el método interpretativo, lo que busca, es comprender la emergencia y existencia de un fenómeno a través de la descripción de procesos. De esta manera, sus preguntas de investigación dan espacio a interrogar por el ¿cómo? Suceden los fenómenos, las maneras, las formas, los detalles, las particularidades. En este paradigma, se hace hincapié en lo micro, en las interacciones individuales, en el comportamiento de los colectivos vistos desde espacios y temporalidades muy concretas. Es por estas razones que se vale de instrumentos tales como la observación, la entrevista, el grupo focal, el análisis documental, entre otras técnicas.

En este estado de cosas, el enfoque que se desea tomar en la investigación es el interpretativo. Las ventajas que este posee se ajustan a la pegunta de investigación, puesto que, la descripción detallada permite conocer a profundidad como ha sido el proceso de madurez del conflicto en Colombia a través de la influencia de las infraestructuras de paz. La técnica utilizada dentro de la amplia gama de métodos cualitativos será el análisis documental, entendido por Gómez (2010) como una selección en diversidad de documentos consultados, con coberturas en el tiempo preestablecidas (para el caso de esta investigación desde los años ochenta que es de donde datan los primeros movimientos sociales por la paz), especificados bajo una temática, y unos descriptores generales sobre los cuales se va a desarrollar la investigación. Los instrumentos de consulta, en donde se plasmaran los contenidos obtenidos de las diversas fuentes, requieren ser construidos de acuerdo a la naturaleza y alcance de las categorías construidas con antelación.

Así pues, este trabajo consta de cuatro apartados: el primero ampliará la tercera coordenada analítica, desglosando los principales elementos constituyentes del concepto de infraestructura de paz, con el objetivo de delimitar su aportación teórica y su articulación a la evidencia empírica seleccionada. El segundo apartado realizará un breve barrido histórico donde se manifieste la presencia de infraestructuras de paz desde la administración de Belisario Betancur (1982-1986) hasta la administración de Juan Manuel Santos (2010-2018). El tercer apartado, se encargará de realizar una pequeña reconstrucción de lo acontecido con las 60 víctimas que viajaron a La Habana con el objetivo de servir como sustento al cuarto apartado, que discutirá lo descrito en aras de desarrollar la hipótesis y propuesta teórica.

\section{Resultados}

\section{Sobre las infraestructuras de paz como concepto teórico}

Jean Paul Lederach (1997), historiador y sociólogo estadunidense; plantea que la construcción de paz es un compromiso de largo plazo que exige la participación de todos los actores y sectores de la sociedad; en otras palabras, para este académico, la configuración de una infraestructura que empodere los recursos para la reconciliación tanto al interior como al exterior del territorio 
es un asunto de capital relevancia. Por ende, caer en un reduccionismo racionalista al creer que a la negociación de paz se llega producto de la necesidad exclusiva de los actores directamente inmiscuidos en la confrontación bélica, es un desconocimiento de los alcances de la guerra en cada una de sus esferas sociales y como consecuencia, la construcción de paz en la etapa de preparación y el posconflicto.

Galaviz (2017) sitúa las infraestructuras de paz como un engranaje que se articula a los tres niveles de gobierno (el local, el departamental y el nacional) en aras del fortalecimiento de la gobernabilidad, la cultura de paz, la participación de la población, los colectivos sociales tradicionalmente excluidos y el fortalecimiento de la sociedad civil en su conjunto.

En este proceso de fomento a la participación, que se constituye bajo la propuesta de trabajo en red, articulador tanto de actores estatales como no estatales. De acuerdo con Tongeren (2012), algunas organizaciones desde las praxis necesarias para configurar infraestructuras de paz son: los comités o concejos de paz (encargados de fomentar el diálogo entre las partes en conflicto además de su reconciliación); los secretariados o ministerios de paz y posconflicto; las comisiones de la verdad (encargadas de la construcción de memoria histórica) e instancias de verificación de la implementación de los acuerdos (Galaviz, 2018).

Adicionalmente, las infraestructuras de paz, pueden analizarse en cualquier etapa del conflicto, la construcción de paz o consolidación de ésta, puesto que su objetivo es verificar la participación de la sociedad civil en la transformación o gestación de instituciones que estimulen el desarrollo humano, la resolución de conflictos y el respeto por los derechos de la ciudadanía (Galaviz, 2018, p.133).

De acuerdo con Pfeiffer (2014), las infraestructuras de paz deben poseer una estructura organizativa, sumada a unas funciones delimitadas. Ambas facetas, deben estar articuladas a la intencionalidad de favorecer las condiciones para la resolución de conflictos y la institucionalización de iniciativas que permitan el desarrollo de capacidades de transformación de las partes en conflicto. La tabla 1 sintetiza las principales características organizativas, sumada a sus respectivas funciones.

\section{Tabla 1.}

Infraestructuras de paz: factores organización y funciones

\begin{tabular}{|l|l|}
\hline Factores Organizativos & Funciones \\
\hline $\begin{array}{l}\text { Formalización de espacios de intervención como criterio de estabilidad } \\
\text { y autoridad }\end{array}$ & Desarrollo de capacidades, asesoría de las partes. \\
\hline Fundamentación nacional & $\begin{array}{l}\text { Facilitación de la comunicación o mediación entre las } \\
\text { partes o actores interesados }\end{array}$ \\
\hline Expresión institucional en todos los niveles & $\begin{array}{l}\text { Contribución a la implementación, monitoreo, o gestión de } \\
\text { actividades acordadas por las partes en conflicto }\end{array}$ \\
\hline $\begin{array}{l}\text { Diferentes grados de inclusión (legitimización y habilidad en el cum- } \\
\text { plimiento) }\end{array}$ & Articulación e incidencia de sectores sociales hacia la paz. \\
\hline
\end{tabular}

Fuente: Elaboración propia a partir de Pfeiffer, 2014

Uribe (2017) plantea la necesidad de inclusión de las infraestructuras de paz desde el diseño mismo de los Planes de Ordenamiento Territorial (POT) y los programas de gobierno a nivel local, puesto que, en muchas ocasiones los modelos de desarrollo adoptados por los distintos gobiernos discrepan con las necesidades reales de las comunidades incrementando los conflictos sociales y la violencia. Véase por ejemplo el caso de las distintas disputas por políticas de corte extractivo en Colombia. Para este autor, las infraestructuras de paz deben ir más allá de la institucionalización de estancias de participación de la sociedad civil, donde la construcción de paz solo se limite al nivel de influencia para que los actores en confrontación puedan resolver el conflicto, es perentoria la construcción de organizaciones de base capaces de transformar sus propios espacios, construyendo paz en sus propios territorios. 
Así pues, de la mano del estímulo de infraestructuras de paz, es oportuno incluir el criterio de fortalecimiento de la estatalidad. Con una sociedad civil con mayor capacidad para gestionar sus conflictos y enfocada en la consolidación de la paz, es más fácil y eficiente la implementación de los acuerdos de paz firmados con las FARC-EP en el marco del florecimiento de múltiples saboteadores. Al respecto, Uribe (2017, p.185) afirma:

Es aconsejable asumir el concepto de infraestructuras de paz como algo más que solo un conjunto de consejos y comités de paz, es decir, como algo más que un sistema complejo: como un sistema complejo adaptativo. Las infraestructuras de paz deben ser contempladas como plataformas amplias para la acción colectiva que, desde provincias y regiones, desarrollen relaciones formales e informales con organizaciones de base y con actores departamentales, nacionales e internacionales, que permitan coordinar decisiones, recursos y procesos para la construcción de paz.

\section{El papel de las infraestructuras de paz en las negociaciones para el fin del conflicto en Colombia (1982-2016)}

La búsqueda de la paz, ha hecho que para el año 1994 el 22\% en las urbes y el 28\% en las zonas rurales de las movilizaciones, sean exigencias de la garantía de la paz como un derecho constitucional (Manrique, 2015). En este orden de ideas, la influencia de actores no estatales en el proceso de madurez del conflicto ha sido notoria. Manrique (2015) plantea que a pesar de las múltiples crisis suscitadas durante la negociación, producto por ejemplo de la reñida contienda electoral que casi le cuesta a Juan Manuel Santos su reelección en el año 2014 y por ende la continuidad de las negociaciones; aunado a las declaraciones de "posible terminación" producto de atentados terroristas por parte de las FARC-EP en medio del conflicto, siempre se evidenció un apoyo de diversas facciones de la sociedad civil al proceso. Este accionar se sintetiza en tres puntos: La ya mencionada reelección presidencial; el papel de las víctimas al interior de las negociaciones y otras múltiples manifestaciones civiles para la construcción de paz, configurándose así como infraestructuras de paz. Como ya se ha insinuado, en el 2014 Santos gana su relección presidencial en segunda vuelta con un $50.9 \%$ de los votos frente un $44.9 \%$ de su directo rival y opositor a los acuerdos, el candidato Oscar Iván Zuluaga (Duque, 2016). Sin duda, este fue un importante espaldarazo de la población al proceso adelantado. Este apoyo se conjuga con el consenso partidario en el cual, la mayoría a excepción de un partido (el Centro Democrático) estuvo a favor de la continuidad de los acuerdos en el congreso.

Sin embargo, este apoyo no se evidenció en el 2016, cuando se formuló el plebiscito para darle legitimidad a los acuerdos pactados. Un alto nivel de abstencionismo ya tradicional en el país concentrado principalmente en la Costa Atlántica, región decisiva en la cual los senadores de la Unidad Nacional no hicieron uso de su maquinaria electoral, al menos de manera contundente, fue uno de los errores políticos de mayor peso (Duque, 2016). Aun así, a pesar de ese traspié, que le dejó como lección a Juan Manuel Santos el no abuso de la confianza al valerse de mecanismo innecesarios, para legitimar algo ya legitimado por la sociedad, los partidos y la constitución política; es oportuno reconocer el papel de las víctimas, organizaciones no gubernamentales y movimientos sociales en el proceso a través de la formación de colectivos que constantemente presionaron para tener voz, voto y reparación dentro de lo pactado.

Si bien las víctimas no han sido el centro del proceso de paz, tal y como ha sido vendido el acuerdo de paz durante el gobierno del expresidente Santos, estas si cumplieron un relevante papel legitimador del proceso. Algunos ejemplos son el caso de la Corporación de Madres de la Candelaria y el Movimiento Nacional de Víctimas de Crímenes de Estado (solo por nombrar algunos botones para la muestra). Estas organizaciones lograron importantes avances encaminados a su reconocimiento, la creación de una comisión histórica para el esclarecimiento del conflicto, además de participación 
directa en las mesas de dialogo, transitando de la reclamación a la participación en la resolución del conflicto (Manrique, 2015). La expresión "las víctimas son el centro del acuerdo de paz" fue recurrente durante los cuatro años de negociación, producto de la participación de las víctimas en distintos foros que se realizaron en varios territorios sumado a las 60 víctimas que tuvieron participación directa en las mesas de negociación. No obstante, las dificultes de inclusión de las víctimas se han evidenciado en el marco del posconflicto. Un letargo parlamentario donde no se aprueban diversos proyectos de ley para que las victimas tengan presencia en estancias como la Jurisdicción Especial Para la Paz (JEP), institución de suma relevancia en el tema de justicia transicional, verdad, justicia y reparación, en anexo a la imposibilidad de que puedan poner en relación directa su experiencia en procesos fallidos como el proceso de paz con ELN; son algunas evidencias de las dificultades que las están dejando por fuera de ese protagonismo que decían promoverse. La dificultad y las reclamaciones de las víctimas, como por ejemplo las del Movimiento Nacional de Víctimas de Crímenes de Estado, es que se ha relegado su presencia como actor político capaz de construir en conjunto con la institucionalidad; aún siguen siendo vistos como beneficiarios de un proceso, de una acción gubernamental o de una política pública (Colombia Plural, 2017).

No son pocos los esfuerzos académicos encaminados a sistematizar estas experiencias y su incidencia en la construcción de paz en Colombia. Distintos investigadores desde sus respectivas universidades, sumados al Centro de Investigación y Educación Popular (CINEP) como tanque de pensamiento experto en esta temática, contribuyendo concretamente con la base de datos "Datapaz"; además, el Observatorio de Construcción de Paz de la Universidad Jorge Tadeo Lozano; el Crupo de Investigación de Memoria Histórica de la Comisión Nacional de Reparación y Reconciliación, entre otros; han hecho ejercicios loables de rastreo de estas iniciativas a lo largo y ancho del territorio nacional (Parra, 2014). La evidencia empírica de este apartado, como suma a lo dicho, se soportará en un breve barrido histórico desde la administración de Betancur como la primera negociación con las FARC-EP hasta las iniciativas de paz durante la negociación en el gobierno de Juan Manuel Santos. Con la negociación de paz de Belisario Betancur (1982-1986), nace tenuemente una infraestructura de paz que se manifestó a través de los defensores de derechos humanos en espacios como el III Foro por el Derecho a la Vida, la Paz y la Apertura Democrática de 1983, el cual exigió al gobierno investigar la actividad de grupos paramilitares como el "MAS" (Muerte A Secuestradores), "los tiznados", "las Boinas Negras" y los Triple A (Villarraga, 2013). El grupo Muerte a Secuestradores fue el primer grupo paramilitar financiado por el narcotráfico con el objetivo de proteger a los distintos capos de estas organizaciones ya terratenientes que tenían nexos con altos dirigentes de los carteles de droga hegemónicos para la época: el cartel de Medellín y el Cartel de Cali. Los secuestradores que se deseaban exterminar eran en su mayoría integrantes de las FARC-EP y el M-19. Las demás facciones nominadas fueron algunas de muchas que empezaron a florecer durante la administración de Belisario Betancur, producto de las supuestas ventajas que se le estaban dando a la insurgencia y del peligro que corrían terratenientes ante el fortalecimiento de la guerrilla a través de la institucionalidad (Velázquez, 2007).

Ya en la administración posterior de Virgilio Barco (1986-1990), las movilizaciones no fueron exclusivas para estimular la negociación con las FARC-EP. Para el caso de los pactos de este gobierno con el Movimiento 19 de Abril (en adelante M-19) en 1989 y el acuerdo político en marzo de 1990 fueron un paso determinante para alentar a la ciudadanía en la perspectiva de la paz y la apertura democrática. Así pues, "La movilización por la paz alentaba los debates y presionaba para que se avanzara decididamente en los acuerdos de paz y las reformas institucionales que le dieran sostenibilidad" (Cinep, 2016a).

En la década de los 90 estas iniciativas tuvieron su auge. El nacimiento de la constitución de 1991, situaba en el mismo escenario la oportunidad de una ampliación democrática en el marco de una mayor inclusión política y, por ende, una real posibilidad de construcción de paz. Este optimismo producido por la génesis de una nueva carta magna, era confrontado por la presencia constante del narcoparamilitarismo. 
Lo que surgió como una respuesta al secuestro y la extorsión por parte de las guerrillas a terratenientes y narcotraficantes en los años 80 , en los 90 se consolidó como un proyecto político, militar y social con la colaboración y complacencia de las fuerzas armadas. Este argumento se soporta empíricamente en la institucionalización del paramilitarismo en una fuerza más compacta como las Autodefensas Unidas de Colombia (AUC) y en el crecimiento exponencial en hombres armados. En la administración de Virgilio Barco, antecesora de la administración de Gaviria, se identifican cerca de 200 organizaciones paramilitares a lo largo y ancho del territorio. Su crecimiento lo estimulo la parsimonia gubernamental, puesto que en la administración Gaviria se declara una lucha frontal contra la insurgencia, pero no contra el paramilitarismo (Velázquez, 2007).

De esta manera, la sociedad civil fue consciente de la necesidad de su influencia. Es en este orden de ideas, partiendo del principio de la joven constitución que situaba a la paz como derecho, que desde el año 1995 organizaciones civiles conformadas por los desmovilizados de las agrupaciones guerrilleras que se sentaron a negociar dieron paso a la búsqueda de la creación del Consejo Nacional de Paz y mesas de diálogo regional en la administración de Ernesto Samper (1994-1998); (Cinep, 2016a). Al respecto Gonyalons (2017, p.23) plantea el siguiente aporte con relación a la administración de César Gaviria:

Proliferaron las iniciativas y aparecieron nuevas organizaciones, a destacar: el Comité de Búsqueda de Paz, que englobaba un importante número de organizaciones sociales y Ong, y la Red Nacional de Iniciativas por la Paz y contra la Guerra (Redepaz), una entidad articuladora de las movilizaciones a nivel regional, que entre otras actividades promovió la Semana por la Paz, un espacio de reflexión que buscaba visibilizar el esfuerzo ciudadano en la construcción de la paz y que se convertiría en una actividad anual.

El Consejo fue creado mediante la ley 434 de 1998, a finales del gobierno de Ernesto Samper. Su objetivo era que distintas facciones de la sociedad civil tuvieran participación, lo cual no debe limitarse exclusivamente a lo que se negocie entre las partes en conflicto. Esta iniciativa, aunque noble, ofreció pocos frutos desarrollándose en escasas reuniones que fueron reactivadas en la administración de Juan Manuel Santos. Su argumento para considerar su reapertura fue el estímulo de: "una participación que movilice a la gente en todas partes, en todas las regiones, alrededor de la construcción de la paz, con proceso de planeación participativa, de abajo hacia arriba en todos y cada uno de los territorios" (Reconciliación Colombia, 2017). En la administración de Andrés Pastrana (1998-2002), las infraestructuras de paz estuvieron más consolidadas. Su nivel de influencia se evidenció en el Mandato por la Paz de 1997 y la Asamblea Permanente de la Sociedad Civil por la Paz en conjunto a movilizaciones de relevancia como por ejemplo: "la ya mencionada Red de Iniciativas contra la Cuerra y por la Paz (Redepaz), la Comisión de Conciliación Nacional y la Ruta Pacífica de las Mujeres son ejemplo de lo que en ese momento dio forma a una compleja y nítida estructura de movilización social por la paz en el país" (Cinep, 2016a, p.17).

Vale resaltar que, la Asamblea Permanente de la Sociedad Civil por la Paz, logró la convergencia de importantes sectores. En él confluyó la iglesia católica, parte de sector empresarial liderado por Ecopetrol (la empresa estatal de petróleo más importante del país), sindicatos y la Oficina del Alto Comisionado para la Paz:

Las propuestas de sectores empresariales durante este período estuvieron encaminadas hacia nuevos enfoques de responsabilidad social, pero debido al aumento de los secuestros de personas de los gremios por parte de las FARC-EP y el ELN, en 1999 se promovió una campaña contra el secuestro que, con apoyo de los grandes medios de comunicación, se convirtió en una masiva campaña contra las FARC-EP bajo el lema "No Más" (Villarraga, 2013; CINEP, 2016b). 
No obstante, este ascenso tuvo su declive, puesto que la movilización fue más expectante de los resultados de la negociación entre el gobierno Pastrana y las FARC-EP, que proactiva. Obviamente, la violencia paramilitar tuvo gran influencia al sabotear los avances de los liderazgos sociales. Si bien hubo participación en las mesas temáticas del Caguán, nunca hubo una representación real en la mesa de negociación. Posteriormente, en la administración de Álvaro Uribe Vélez (2002-2010) y su política de Seguridad Democrática, donde se redujo el secuestro y el apogeo militar de las FARC-EP, en contraste con el aumento del desplazamiento forzado y el aumento del abuso por parte de agentes del Estado, con hechos penosos y lamentables como los "Falsos Positivos", se consolida la movilización de las víctimas como un actor político trascedente, aunque se reducen considerablemente las iniciativas ciudadanas en aras del estímulo de la búsqueda de la negociación política (CINEP, 2016a).

Omar Eduardo Rojas, oficial de la policía con más de 30 años de servicio, documentó cerca de 10.000 casos de ejecuciones extrajudiciales, en su libro Ejecuciones extrajudiciales en Colombia, 2002-2010. Obediencia a ciegas en campos de batalla ficticios:

Este autor describe cómo el Ejército de Colombia mató sistemáticamente a civiles para aumentar sus recuentos de cadáveres. Rojas menciona que fueron asesinados a sangre fría de civiles, asesinatos meticulosamente planificados y llevados a cabo por todos los rangos militares. Rojas dijo que incluso niños con discapacidad fueron específicamente atacados aprovechándose de su vulnerabilidad. Lo mismo dice ocurrió con un puñado de militares sospechosos de denunciar (BluRadio, 2018).

Por último, en la negociación de La Habana, en la administración de Juan Manuel Santos, la movilización para estimular la firma de un acuerdo de paz se reactiva en todos los años de la negociación, demostrando que el perfil político del gobernante y la noción que este posea del conflicto es de gran importancia para determinar las garantías y posibilidades de movilización. A continuación, la figura 1 esquematiza el conjunto de acciones de iniciativa por la paz en las distintas administraciones presidenciales, desde Belisario Betancur (1982-1986) hasta Juan Manuel Santos (2010-2018).

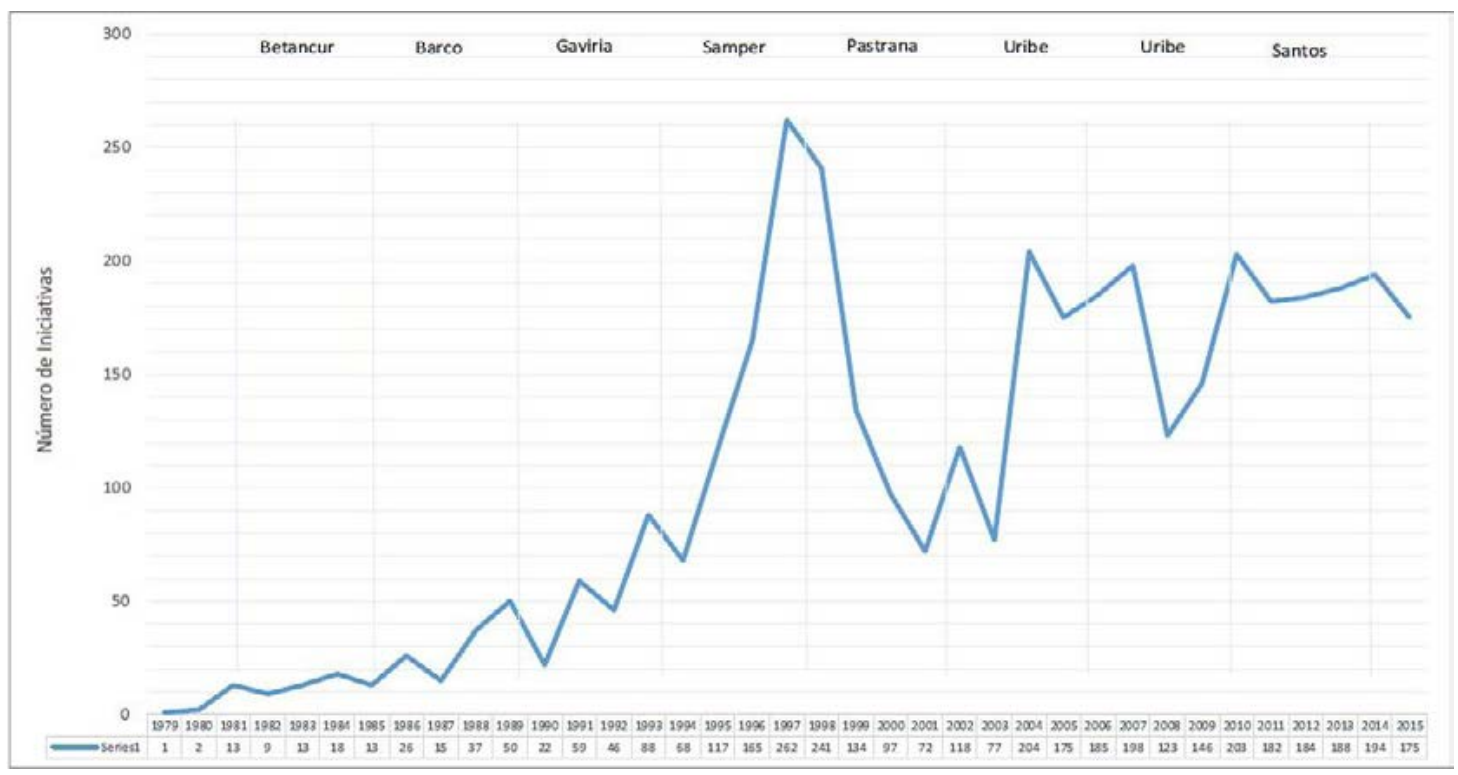

Figura 1. Iniciativas de paz en el transcurso de Betancur a Santos.

Fuente: CINEP (2016a).

Es válido dejar claro que las infraestructuras de paz no son acciones colectivas espontáneas, sin trascendencia y duración en el tiempo. Los actores y las acciones que son sistematizadas por el 
Cinep (2016a), son emprendimientos producto de organización y frecuencia. Metodológicamente, una iniciativa de paz es sistematizada como infraestructura si cumplen con las siguientes condiciones: 1. el evento, acto, acción es considerada por la organización como iniciativa de paz (criterio de autodefinición). 2. El evento es considerado explícitamente como una iniciativa formulada e implementada para rechazar expresiones de violencia; tomar conciencia o visualizar, discutir o demandar una iniciativa de paz. 3. La acción colectiva es registrada en la base de datos del CINEP y es documentada por periódicos regionales y nacionales (Cinep, 2016a).

Los distintos sectores y organizaciones sociales a lo largo y ancho del territorio colombiano sumaron, para el caso de la negociación entre las FARC-EP con el gobierno de Juan Manuel Santos, un total de 970 apariciones (333 en los años 2012-2013, 278 en los años 2014-2015 y 339, en los años 20152016); configurándose como más de la mitad de las acciones realizadas por actores no estatales. Como segundo actor de relevancia aparecen las organizaciones no gubernamentales y los defensores de derechos humanos con 118 apariciones. Otros actores de influencia de carácter internacional, sumados a la iglesia, partidos y movimientos políticos, entre otros, son ubicados en la tabla (2) mostrando su nivel de relevancia como soporte de las infraestructuras que apoyaron el proceso de paz.

Tabla 2.

Actores e iniciativas de paz en Colombia (2012-2015).

\begin{tabular}{|c|c|}
\hline ORGANIZACIÓN & PORCENTAJE DE PARTICIPACIÓN \\
\hline Sectores y organizaciones civiles & $51.5 \%$ \\
\hline Órganos gubernamentales ejecutores & $20.3 \%$ \\
\hline Partidos y movimientos políticos & $6.4 \%$ \\
\hline Entes privados & $6 \%$ \\
\hline Actores internacionales & $5.4 \%$ \\
\hline Iglesia & $3.2 \%$ \\
\hline Órganos con protesta normativa & $3.2 \%$ \\
\hline Organizaciones de carácter mixto & $4 \%$ \\
\hline TOTAL & $100 \%$ \\
\hline OTROS ACTORES & ACTIVIDADES CONTABILIZADAS \\
\hline Entidades culturales y deportivas & 78 \\
\hline Organizaciones de jóvenes & 65 \\
\hline Estudiantes & 49 \\
\hline Mujeres & 46 \\
\hline Pobladores urbano-rurales & 39 \\
\hline Campesinos & 34 \\
\hline Niños(as) & 34 \\
\hline Indígenas & 29 \\
\hline Académicos e intelectuales & 26 \\
\hline Gremios económicos & 19 \\
\hline Organizaciones sindicales & 12 \\
\hline Trabajadores independientes & 12 \\
\hline Afrocolombianos & 8 \\
\hline Otros Actores & 34 \\
\hline TOTAL & 485 \\
\hline
\end{tabular}

Fuente: elaboración propia a partir de CINEP (2016a). 
Vale aclarar, de la tabla expuesta, que la categoría "Organizaciones de carácter mixto" es comprendida por las fuerzas armadas y de policía; Organismos de control y vigilancia del Estado y Estados y entidades gubernamentales. Se denominan de carácter mixto y gubernamental pues son iniciativas de paz coordinadas por entidades del Estado propiamente o en colaboración con sectores de la sociedad civil. Así mismo, a la categoría "otros actores" se suman desmovilizados, desplazados, líderes sociales, comunidad LGBTI, comuneros y ambientalistas.

Ahora bien, en la administración de Juan Manuel Santos, las iniciativas de paz tuvieron sus altas y bajas. Para el 2012, año en el que inicia la negociación, se contabilizaron en la base de datos del Cinep (2016b) un promedio de 16 acciones por mes. Esta cifra que es considerada alta, se configura en el marco de una incipiente negociación que levantaba una alta expectativa para un amplio sector de la opinión pública colombiana.

En el año 2013, esta cifra baja a un aproximado de un total de 15.7 acciones, debido a algunos factores asociados a la negociación en medio del conflicto y que la mesa de negociación tuvo un receso de un mes entre abril y mayo, dejando en la opinión pública una sensación de crisis. No obstante, hubo un alza al anunciarse en ese mismo año, la definición y acuerdo respecto al segundo punto de la mesa de negociación: la participación política de las FARC-EP. El año 2014 fue de suma relevancia para poner a prueba la consolidación de las infraestructuras de paz. Con un Juan Manuel Santos en aprietos, derrotado en primera vuelta por un opositor del proceso de paz, el candidato del Centro Democrático (partido de Álvaro Uribe) Oscar Iván Zuluaga, fue fundamental la exhortación de distintos sectores de la sociedad civil y partidos políticos a votar por Santos para consolidar una negociación que ya tenía avances, pero que todavía no había materializado la firma de un acuerdo. Es así como Juan Manuel Santos es reelegido por un estrecho margen y logra dar continuidad a la negociación. En el 2015, en medio de contrastes producto del comportamiento desleal de las FARCEP atacando oleoductos en Nariño y Putumayo, con un ya acordado cese al fuego, la opinión pública fue relativamente pesimista la primera mitad del año. Afortunadamente, para el mes de agosto se anuncia una fecha tentativa para la firma del acuerdo (23 de agosto del 2016) lo cual estimuló nuevamente la movilización.

Las formas en cómo se manifestaron las distintas iniciativas fueron plurales, teniendo un factor común: su proceder pacifico. Marchas, encuentros, foros, seminarios, eventos deportivos y culturales entre tantos otros fueron desarrollados principalmente en los departamentos de Antioquia, Valle del Cauca, Cauca, Santander y Bolívar. A continuación la tabla 3 manifiesta la cuantificación de cada una de estas actividades, en los tres años reseñados (2012 al 2015). Por su parte la figura 2 muestra las infraestructuras de paz por departamentos. Es oportuno aclarar, que los motivos de la movilización fueron principalmente en rechazo a la violencia, al estímulo del mantenimiento de la negociación, la promoción de una cultura de paz y la búsqueda de alternativas al conflicto y el subdesarrollo. 
Tabla 3

Iniciativas de paz por tipo y número (2012-2015)

\begin{tabular}{|l|l|}
\hline Tipo de iniciativa & Número \\
\hline Marchas y concentraciones & 123 \\
\hline Encuentros, foros y seminarios & 99 \\
\hline Actos culturales y deportivos & 96 \\
\hline Campañas y acciones educativas & 63 \\
\hline Acciones de acción y coordinación & 35 \\
\hline Acciones de memoria & 35 \\
\hline Diálogos y negociaciones, premios y homenajes & 35 \\
\hline Celebraciones y actos religiosos & 12 \\
\hline Comunicados colectivos & 9 \\
\hline Concertaciones ciudadanas & 3 \\
\hline Acciones de resistencia civil, parosy huelgas & 6 \\
\hline Acciones de participación electoral & 2 \\
\hline Declaración de Zona de paz & 1 \\
\hline Total & 519 \\
\hline
\end{tabular}

Fuente: Elaboración propia a partir del CINEP (2016a)

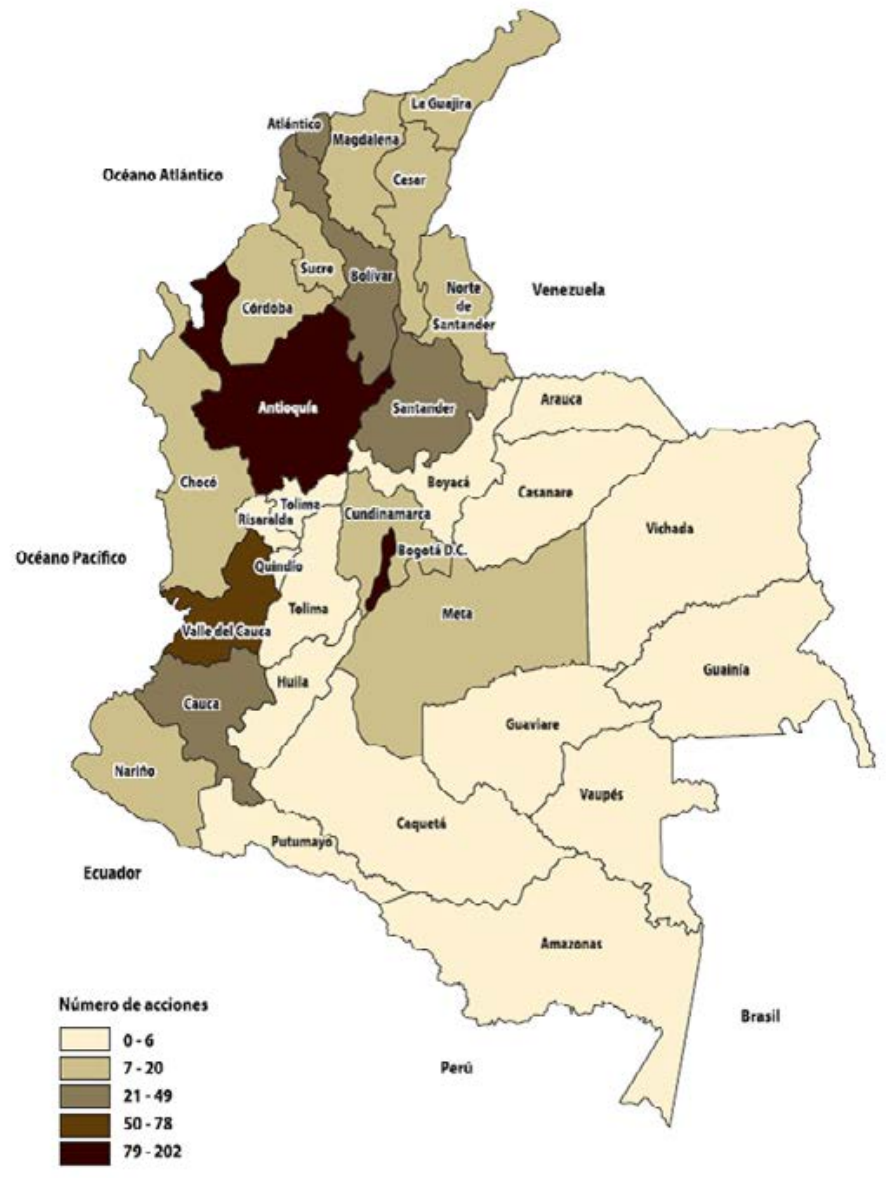

Figura 2

Iniciativas de paz por regiones 2012-2015

Fuente: CINEP, 2016a. 


\section{El papel de las víctimas en la negociación de La Habana}

Es interesante dejar en evidencia, la transición en condiciones de especificidad que tuvieron las infraestructuras de paz, pasando de la organización social materializada en los múltiples actores que ya se describieron (plurales y diversos), al rol concreto que tuvieron las víctimas en la negociación de paz en La Habana.

Dicha participación fue un evento inédito no solo en Colombia, en las negociaciones previamente descritas con las FARC-EP, sino también en negociaciones con otras guerrillas. Si bien, las negociaciones en el marco de la constitución de 1991 fueron relativamente incluyentes, las víctimas del conflicto como actores políticos en ese momento no aparecían en el espectro de una resolución de un conflicto político. Esa novedad no solo se evidencia en la historia colombiana, puesto que el rol de las victimas tampoco fue explorado en negociaciones de la región latinoamericana como El Salvador o Guatemala, por ejemplo.

Es por estas razones que se considera oportuno, realizar una breve descripción de cómo fue la participación de las víctimas en La Habana y el rol que tuvieron para dar un buen fin a la negociación. En conjunto a la descripción, del rol que tuvo la negociación internacional en los momentos de crisis, siempre presentes en estos escenarios. De los siete millones de víctimas contabilizadas en las múltiples décadas de conflicto, solo 60 fueron a la negociación de La Habana. Las mismas se dividieron en tres delegaciones que fueron conformadas con asesoría del Programa de Naciones Unidas Para el Desarrollo (PNUD); la Universidad Nacional de Colombia y la Conferencia Episcopal. Al respecto, Verdad Abierta (2014) apunta:

Militares, empresarios, sindicalistas, religiosos, académicos, periodistas y personas del común estuvieron en La Habana. De los 60 no sólo hubo afectados por la Fuerza Pública y las FARC-EP, sino también por paramilitares, el Ejército de Liberación Nacional (ELN), bandas criminales y un único caso de una comunidad afectada por multinacionales mineras.

De las 60 víctimas, 25 eran hombres y 36 eran mujeres; 13 de ellos fueron amenazados, 7 sufrieron atentados, 6 fueron sometidos a desaparición forzada, 19 fueron desplazados, 2 eran familiares de personas sometidas a ejecución extrajudicial, 19 familiares de personas asesinadas en el marco del conflicto y 8 por masacres; 2 por minas antipersona y 2 por reclutamiento forzado, 10 por secuestro, 5 por tortura y 4 por violencia sexual. A continuación, la figura (3) muestra la dispersión de las victimas escogidas por región. 


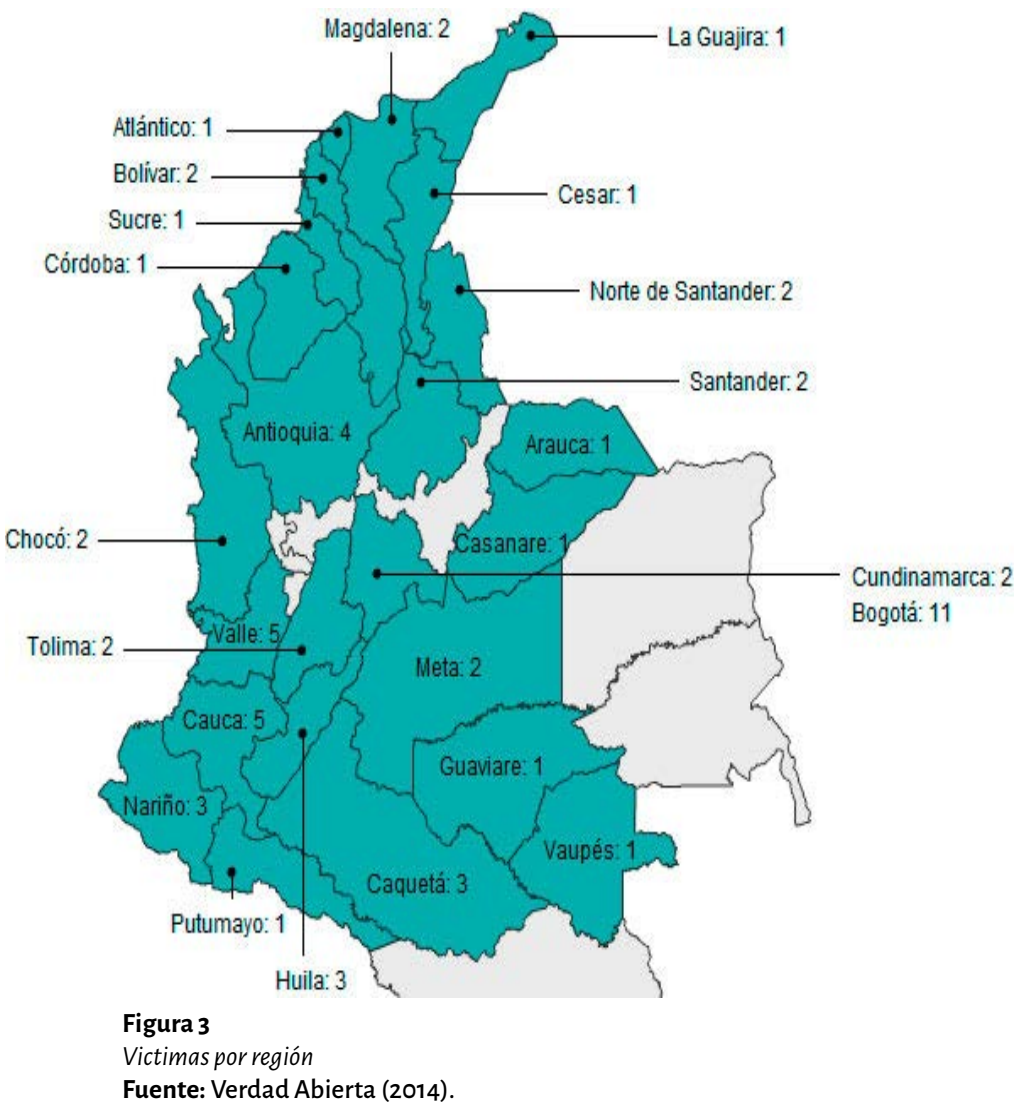

Brett (2017) apunta que el impacto que tuvo la participación de las víctimas en la negociación de La Habana tuvo repercusión en tres aspectos: el individual, al interior de las conversaciones y un impacto negativo hacia las víctimas a posteriori. El impacto individual fue principalmente de carácter sicológico en aras de la reparación y la reconciliación. Sin duda, es un ejercicio valioso el poder interactuar víctima y victimario en un mismo espacio, intercambiando ideas, hablando de lo sucedido en cada situación y sobre todo, construyendo vínculos de empatía. Varias de las víctimas, respecto a este punto, manifestaban una sensación de paz interna, de tranquilidad y descanso. Así lo expreso Luz Marina Cuchumbé. Otra de las víctimas, Gloria Londoño, afirmó una sensación similar:

Cuando iban terminando los testimonios de las víctimas y hubo un descanso se acercaron a varios de nosotros miembros del gobierno o de las Farc y dirigieron una palabra y pudimos conversar. En ese interactuar ya no veías a la persona por tener una función o tener una marca del gobierno o marca de las Farc o marca de víctima, sino fue una relación de iguales, como seres humanos (Brett, 2017, p.56).

Lo interesante del asunto radica, en que más allá de la empatía del victimario hacia la víctima, se generó también un intento inverso, donde la victima realizó la difícil tarea de comprender el accionar de su victimario, rebasando el odio infundido con cierto éxito por los opositores de la paz (el Partido Centro Democrático) a través de medios de comunicación y desinformación que hicieron que el NO ganara el plebiscito por la paz del año 2016. La víctima Eliecer Velázquez, al respecto, presenta su testimonio:

Yo tuve la oportunidad de sentarme a hablar con algunos de ellos y en lo que nosotros hablamos pude tener la concepción que somos los mismos colombianos. De alguna manera ellos hicieron eso porque 
estaban defendiendo también su pueblo, y ellos reclamaban sus derechos y nosotros precisamente, y tuvieron que alzarse en armas porque el Estado los quería acabar (Brett, 2017, p.59).

De acuerdo a lo planteado por Monseñor Castro, presidente de la Conferencia Episcopal, las actitudes de las partes antes en conflicto y ahora en conversaciones de paz fue evolucionando con la presencia de las víctimas. Se pasó de una actitud defensiva tanto de la guerrilla como del gobierno a un reconocimiento de los errores cometidos: Las FARC-EP reconoció el sufrimiento generado a tanta gente, mientras que los representantes del Estado aceptaron su falencia en el cumplimiento de su deber constitucional de garantía de la seguridad. Monseñor afirmó: "hubo un proceso de maduración en la mesa que creo va a ser muy útil para llegar a los acuerdos, eso todo fue el fruto del encuentro con las víctimas" (Brett, 2017, p.66).

Sin duda, el mayoraporte de las víctimas fue la visibilidad que lograron al interior de las negociaciones, fortaleciendo el punto de víctimas, que hace parte del acuerdo final. De alguna manera, ellas mismas fueron protagonistas de su propia inclusión. El compromiso con la memoria histórica del país se amplió, exigiendo garantías de no repetición y una justicia transicional más afinada en relación con los actores directos e indirectos más afectados por el conflicto. Al respecto, Leyner Palacios nos explica:

La justicia que nosotros las victimas buscamos, no es una justicia que obstaculice el proceso de Paz. Yo pienso que la paz tiene que tiene que ser superior a las ansias de justicia. Sin embargo pues también, hay que mantener un pequeño equilibrio, no podemos llegar a un nivel de justicia tan bajo, que incluso deteriore la dignidad de las víctimas. En esencia la justicia tiene que ser una justicia restaurativa (Brett. 2017, p.72)

Finalmente, se debe destacar el último punto, relacionado con la negatividad de la participación en la negociación. Sin duda, el papel de víctima en La Habana era traumático por donde se le viera. Por un lado era confrontar a victimarios recordando hechos sumamente traumáticos, reviviendo momentos de gran estrés y dolor. Por otro lado era exponerse a morir a manos de grupos opositores de la paz; concretamente asesinatos ejecutados por mercenarios y sicarios agrupados en las "águilas negras".

Respecto a la empresa de tratar de desenmarañar quienes son las "águilas negras", el investigador Ariel Ávila (2018), de la Fundación Paz y Reconciliación afirma:

Las Águilas Negras no existen como estructura criminal. No existe ningún registro de campamentos, líderes o comandos armados que revelaran su existencia. En cambio lo que se encontró es que: Algunos grupos criminales, cuando van a hacer operaciones criminales que dejen muchos muertos o que sean muy violentos, se ponen el nombre de Águilas Negras para no ser identificados. Hay sectores en la legalidad, como supuestos empresarios, políticos o particulares, que contratan sicarios para asesinar o amedrantar personas, y se hacen colocar el nombre de "Águilas Negras". Además, Se encontraron evidencias de agentes institucionales que utilizan panfletos con el nombre de "Águilas Negras" para amedrentar comunidades, individuos e incluso grupos de jóvenes con comportamientos violentos. También se encontraron que este nombre de Águilas Negras es utilizado por particulares, mediante panfletos, para infundir miedo a diferentes comunidades.

Así pues, desde la institucionalidad todavía no se ha definido con rigor quienes son y cómo combatir todas estas formas de criminalidad que se hacen llamar de la misma manera. De las 60 víctimas, 14 recibieron amenazas por su participación, todos fueron protegidos por una unidad de 
protección del gobierno nacional. Por fortuna, ninguna víctima participante de las negociaciones de La Habana ha sido asesinada.

Con lo anterior, se evidencia que la participación de las victimas en terminos específicos y las infraestrucutras de paz, en términos generales, tuvieron un papel de estímulo a la negociación y a su continuidad en la etapa previa a la misma con todas las iniciativas de paz encaminadas a su promoción documentadas desde las primeras negociaciones con Belisario Betancur. Hasta ese momento, la participación en relación con la paz estaba supeditada a la expectativa, a la presión por la continuidad en momentos de crisis. En un segundo momento, fueron fundamentales durante las conversaciones perfeccionando los acuerdos logrados, dotandolos de mayor humanidad y sirviendo de legitimadores en la etapa de consolidación de la paz, una vez firmado el acuerdo.

\section{Conclusiones}

Los grupos de presión, a diferencia de los partidos, solo pretenden influir el sistema político. De acuerdo a planteamientos esbozados hace ya varias décadas por clásicos de la Ciencia Política, como es el caso de Almond y Powell, los hay anómicos, espontáneos, no asociativos, informales, intermitentes e institucionalizados. El acto de influir, lo denota la intencionalidad de desarrollo del uso (o amenaza) de sanciones en las decisiones del poder político a fin de cambiar servicios, cargas o situaciones (Ruízy Vanaclocha, 1989).

Las infraestructuras de paz, desde su génesis en la administración de Belisario Betancur, han sido grupos de presión de carácter privado (y mixto en menor medida), que está en una constante lucha por constituirse como un actor político con un grado mayor de institucionalización, valiéndose de la movilización social de manera pacífica. Esta intencionalidad de institucionalización se evidenció en el salto cualitativo que dieron en la administración de Juan Manuel Santos, pasando de su configuración de apoyos de los procesos de paz, a mediadores en el escenario de negociación. Sin duda, la influencia de las víctimas en La Habana jugó un papel de estabilización de los actores directos del conflicto, logrando reconocimiento de errores y fortaleciendo los procesos de reconciliación y justicia transicional al menos en esa estancia: la negociación en sentido estricto.

En este apartado final, que es el que condensa el carácter analítico de este trabajo, se pretende reflexionar sobre dos asuntos de relevancia: la primera es la evidente articulación teórica desde la evidencia empírica que tiene el concepto de infraestructuras de paz como grupos de presión con el de madurez del conflicto (Appropriate Timing) como etapa analítica de construcción de paz; la segunda es la carencia de institucionalización que han tenido las infraestructuras de paz a pesar de sus múltiples esfuerzos por tener presencia como actores directos en el proceso de implementación del acuerdo firmado. Christopher Mitchell sitúa la madurez del conflicto como el proceso mediante el cual las partes en confrontación, que en algún momento estuvieron reticentes a abandonar la disputa, deciden de manera voluntaria llegar a un acuerdo negociado. Al respecto plantea: "se entiende que un conflicto está maduro para su resolución cuando se dan un conjunto de circunstancias apropiadas" (Mitchell, 1996, p.6). Su entramado teórico se compone de dos enfoques de abordaje: el primero es uno de corte sistémico, encargado de revisar el proceso de madurez del conflicto desde una perspectiva histórica buscando puntos de quiebre donde se pasa de la confrontación bélica a las posibilidades reales de la negociación y firma de un acuerdo de paz, y el enfoque de toma de decisiones, propuesta inminente racionalista, donde se busca determinar las razones por las cuales la diada en conflicto considera oportuno pasar de la guerra a las conciliación. Se cita a este autor, porque él, junto con Zartman (1991) son referentes clásicos de obligatoria consulta para comprender los procesos de preparación para la paz y madurez del conflicto. Sin embargo, en sus abordajes no se evidencia hasta el momento el reconocimiento de la influencia de las infraestructuras de paz en los procesos de madurez del conflicto. Tampoco es oportuno esbozar una crítica, puesto que la relación 
infraestructura de paz y madurez del conflicto, es una particularidad del caso colombiano, concretamente del conflicto entre las FARC-EP y las distintas administraciones presidenciales.

Si bien explicar las razones por las cuales las FARC-EP se sentaron a negociar después de tres intentos fallidos con intenciones reales de dar fin al conflicto, se soportarán principalmente en la explicación militar propias de la guerra de desgaste producto de la política de seguridad democrática de Álvaro Uribe Vélez, materializada en la baja de hombres armados (algunos desmovilizados) y pérdida de milicianos, la deslegitimación de su lucha ante la opinión pública a través de medios de comunicación, la muerte natural y en combate de importantes cabecillas, la modernización del ejército a través del "Plan Colombia"y "Plan Patriota" y la instauración de presencia de fuerza públicas en territorios donde antes el Estado no tenía presencia. Es oportuno esbozar que las infraestructuras de paz tuvieron un rol complementario como actores no estatales capaces de legitimary apalancar estos procesos de paz una vez se dieron las condiciones políticas para hacerlo viable. El enfoque de toma de decisiones de la teoría de madurez del conflicto, desde una perspectiva puramente racionalista, se queda corto ante la complejidad de explicación del porqué se pudo negociar la paz en Colombia en el año 2016, puesto que plantea la negociación de paz como un juego estratégico propio del desgaste de la guerra, elemento importante, pero no el único capaz de permitir la comprensión de las razones que incentivaron la negociación (Molina, 2019). Así pues, las infraestructuras de paz, como grupos de presión y actor político con vocación de institucionalización, estuvieron presentes durante cada una de las negociaciones con las FARC-EP, siendo apoyos en la coyuntura histórica y las dinámicas propias de la particularidad de cada administración presidencial.

Hodgson (2011) plantea que:

por lo general, las instituciones hacen posible el pensamiento ordenado, las expectativas y la acción al imponer a las actividades humanas una forma y una consistencia. La existencia de reglas implica unas restricciones. Sin embargo, dichas limitaciones pueden abrir posibilidades: pueden promover elecciones y acciones que de otra manera no existirían (pp.22-23).

Las infraestructuras de paz como iniciativas civiles promovían la ampliación de las posibilidades que la paz buscaba al firmarse, consolidando una mayor acogida por el conjunto de la población colombiana a la cabeza de las facciones de la sociedad que se han visto afectadas mayormente por el conflicto armado.

La búsqueda de la institucionalización que se menciona en el presente artículo, consiste positivamente en su capacidad organizativa y operativa en el transcurso de la historia colombiana, siendo recurrentes en su presencia a través de la manifestación pacífica, por medio de su capacidad para hacerse notar, al punto de tener una presencia inédita en la negociación de La Habana. Esto es loable, no sólo en el contexto colombiano, sino en los países latinoamericanos que han tenido conflicto armando y han buscado su salida negociada. No obstante, su alcance no llega a la hora de tener incidencia en la ejecución de la política pública, es decir en la etapa de implementación del acuerdo.

Uribe (2017) ha sido claro al destacar que la noción de infraestructura de paz, es vista desde el ambiente académico como la sociedad civil organizando actividades para apoyar iniciativas de resolución de conflictos y una cultura de paz a nivel territorial, departamental o nacional. Lamentablemente, esta noción rebaja su alcance, importancia y aporte al posconflicto. Así como las victimas ocuparon un papel importante en La Habana, logrando un mayor reconocimiento de la insurgencia y el gobierno de sus fallas y errores, logrando mejorar lo que sería el acuerdo de paz más adelante, se hace necesaria su presencia en estancias institucionales como la Justicia Especial para la Paz (en adelante JEP); el congreso de la República (con los representantes de las víctimas) y el estímulo respectivo a nivel territorial de todas las iniciativas para que la paz no sea menoscaba$\mathrm{da}$, producto de las acciones de la gran cantidad de saboteadores que hay actualmente del proceso, 
organizados en disidencias de las FARC-EP y el paramilitarismo; el ELN y la delincuencia organizada presente en los lugares donde el Estado nunca ha tenido presencia; y hoy, son una muestra palpable de que la paz no llega con la firma de un documento. Este es el punto de la institucionalización de las infraestructuras de paz, proceso que cada vez cobra más necesidad.

Las víctimas, en términos concretos, y las infraestructuras de paz, en términos generales, se han especializado en ser grupos de presión capaces de influir lo suficiente para hacer parte del proceso de reparación y reconciliación que exige el posacuerdo. Sin embargo, su fuerza no se materializa en su capacidad de hacer cumplir lo pactado. Por ejemplo, en el tema de las circunscripciones especiales para la paz, donde se le garantizaba presencia a las víctimas a través de curules en el congreso, fue archivada por no aprobación de este órgano legislativo a pesar de la existencia de normatividad que obligaba a votar positivamente (Rodríguez, 2018).

Sin duda, la institución que más demanda la participación de las víctimas como consecución del esfuerzo histórico de las infraestructuras de paz, es la JEP. Su presencia es fundamental para la garantía de un verdadero proceso de reconciliación y justicia transicional eficiente. En este contexto, la victima trasciende de apoyo legitimador a sujeto de derechos, fortaleciendo la verdad, con la evidencia de pruebas, sin caer en el reduccionismo de tratarla como mera testigos, configurándose como parte activa de un proceso real de justicia (Ospina, Linares y Maldonado. 2017). La JEP como institución, tiene un papel protagónico para esta fase de construcción de paz, a la fecha su presencia todavía se encuentra en etapa de construcción. Finalmente, se concluye con las siguientes afirmaciones: la primera es que las infraestructuras de paz en Colombia han recorrido un importante camino como grupo de presión en la historia reciente. No obstante, la fase de posconflicto demanda su presencia como actores directos, el problema radica en las intenciones del gobierno y órganos legislativos de darles dicho reconocimiento. La segunda es que términos teóricos, las infraestructuras de paz en Colombia, pueden tener una articulación interesante con la teoría de madurez del conflicto, ampliando su alcance explicativo complementando cualquiera de los dos enfoques de abordaje propuestos por Mitchell. Futuros trabajos permitirán ampliar en esta afirmación.

La tercera es que el camino que queda por recorrer, debe ser forjado de la misma manera como ha sido demarcado en el pasado, es decir, con la movilización social. La reciente acción del congreso de la república en su ambigüedad de negar las jurisdicciones especiales para las víctimas es muestra de la intención de negar el carácter político de ciertas facciones de la sociedad civil que fueron afectadas por el conflicto armado. Sin duda, las infraestructuras de paz son un actor en vía de institucionalización que busca incrementar su estatus político, su avance permitirá una construcción de paz desde la base, con un enfoque de abajo hacia arriba, siendo más eficiente, puesto que las infraestructuras de paz se forjan en los territorios, mismos que les son esquivos al Estado a ser medida su presencia.

El paso del gobierno de Juan Manuel Santos al gobierno de Iván Duque es un obstáculo para el proceso nominado dado el perfil de realismo político (imposición de la paz a través de la vía militar) que en general ha venido manejando el uribismo desde inicios de siglo. No obstante, las víctimas y colectivos civiles deben reproducir su experticia tal y como lo plantea el coordinador de la mesa de víctimas del departamento de Bolívar:

Al presidente de Colombia le va a quedar muy duro ignorarnos, porque por cualquier vía demostraremos que ahí estamos y que hemos pasado por mucho para dejar que los avances gigantescos que se han logrado, se vaya a perder en un abriry cerrar de ojos" (Rodríguez, 2018). 


\section{Referencias bibliográficas}

Ávila, A. (29 de diciembre de 2018). ¿Qué son las Águilas Negras? Obtenido de sitio web de Fundación Paz y Reconciliación: https://pares.com.co/2018/08/07/que-son-las-aguilas-negras/

BluRadio. (9 de mayo de 2018). Falsos positivos serían más de 10.000, según coronel retirado. Obtenido de sitio webdeBluRadio: https://www.bluradio.com/nacion/falsos-positivos-serian-mas-de-10-0o0-segun-coronel-retirado

Brett, R. (2017). La voz de las víctimas en la negociación: sistematización de una experiencia. Bogotá: Programa de las Naciones Unidas Para el Desarrollo (PNUD).

Cadavid, A. (2015). La mesa ecuménica por la paz. Una expresión de la fe del pueblo empobrecido. Revista Kavilando, 7(1), 53-56. https://www.kavilando.org/revista/index.php/kavilando/article/view/32

CINEP. (2016a). Movilización por la paz en Colombia: una infraestructura social clave para el posacuerdo. Bogotá: Centro de Investigación y Educación Popular/Programa por la paz.

CINEP (2016b). Banco de datos CINEP [Base de datos del Banco de datos]. Centro de Investigación y Educación Popular/Programa por la paz. Bogotá.

Colombia Plural. (14 de febrero de 2017). "Las víctimas ya no estamos en el centro del proceso de paz". Obtenido de sitio web de Colombia Plural: https://colombiaplural.com/las-victimas-ya-no-estamos-centro-del-proceso-pazl

Della Porta, D. y Keating, M. (2008). Enfoques y metodologías de las ciencias sociales: una perspectiva pluralista. España: Ediciones Akal.

Duque, J. (3 de octubre de 2016). Un plebiscito innecesario, una derrota inesperada. Obtenido de sitio web de Razón Pública: https://razonpublica.com/un-plebiscito-innecesario,-una-derrota-inesperada/

Fundación Paz y Reconciliación. (2018). Cómo va la paz. Bogotá: Fundación Paz y Reconciliación/La iniciativa, Unión por la paz.

Galaviz, T. (2013). La interacción de la confianza en los procesos de consolidación de la paz. Iberofórum. Revista de Ciencias Sociales de la Universidad Iberoamericana, 16 (VIII), 35-76.

Galaviz, T. (2017). Infraestructuras para la paz, herramientas de participación social. Inventio, la génesis de la cultura universitaria en Morelos, 13(31), 5-12.

Galaviz, T. (2018). Infraestructuras para la paz y justicia transicional en Colombia. Reflexiones, 97(2), 123136.

Galtung, J. (1998). Tras la Violencia 3R: Reconstrucción, Reconciliación, Resolución. España: Gernika Gogoratuz.

Cómez, L. (2010). Un espacio para la investigación documental. Revista Vanguardia Psicológica Clínica Teórica y Práctica, 1(2), 226-233.

Grasa, R \& Mateos, O. (2011) Guía para trabajar en la construcción de la paz. Qué es y que supone la construcción de la paz. Cómo afrontar el tránsito de hacer las paces a construir la paz. Bogotá: Instituto Catalán Internacional para la Paz/Cámara de Comercio de Bogotá.

Hodgson, G. (2011). ¿Qué son las instituciones? Revista CS, 8, 17-53.

Lederach, J. (1997). Construyendo Paz: Reconciliación Sostenible en Sociedades Divididas. Washington, D.C: Institute of Peace.

López, M. (2011). Teorías para la paz y perspectivas ambientales del desarrollo como diálogos de imperfectos. Luna Azul, 33, 85-96.

Manrique, M. (2015). La sociedad civil colombiana en los diálogos de paz en La Habana, Cuba. Anuario en Relaciones Internacionales del IRI, 2015.

Mitchell, C. (1996). Evitando daños: reflexiones sobre la situación de "madurez" en un conflicto. España. Centro de Investigación por la Paz "Cernika Cogoratuz".

Molina, J. (2019). Exploración a las condiciones de madurez del conflicto entre las FARC-EP y el gobierno de Colombia (1982-2016) (Tesis de Maestría). Universidad Autónoma del Estado de Morelos. México.

Muñoz, F (Ed.). (2001). La paz imperfecta. España: Universidad de Cranada, Colección Irene.

Ospina, J. Linares, C. Maldonado, J. (2017). Promoviendo la garantía y exigiendo los derechos: Cuía para profesionales en el SIVJRNR. Bogotá: Comisión Colombiana de Juristas. 
Parra, L. (2014). Prácticas y experiencias colectivas ante la guerra y para la construcción de paz: iniciativas sociales de paz en Colombia. El Ágora USB, 14(2), 377-395.

Pfeiffer, S. (2014). Infraestructura de Paz en Colombia. Berlín: Berghof Foundation.

Reconciliación Colombia. (2017). Se reactiva el Concejo Nacional de Paz. Obtenido de sitio web de Reconciliación Colombia: http://reconciliacioncolombia.com/web/historia/1573/se-reactiva-el-consejo-nacional-de-paz

Rodríguez Bernal, D. (18 de junio de 2018). Víctimas del conflicto, el mayor reto del gobierno de Iván Duque. Obtenido de sitio web de Radio Nacional de Colombia: https://www.radionacional.co/noticia/ presidenciales-2018/victimas-mayor-reto-del-gobuerno-de-ivan-duque

Ruíz, M. \& Vanaclocha, F. (1989) Los actores políticos y sociales. En: García, R \& Paniagua, ] (compiladores), Introducción a la Ciencia Política. Madrid: Universidad Nacional de Educación a Distancia.

Semanario Voz. (20 de junio de 2018). Avanzan las fuerzas democráticas. Obtenido de sitio web de Semanario Voz: http://semanariovoz.com/avanzan-las-fuerzas-democraticas/

Tongeren, P. (2013). Background Paper on Infrastructure for Peace. Paper presented at the Seminar on Infrastructure for Peace, part of the Sixth Camip Summit, Clobal Alliance for Ministries and Infrastructures for Peace. Geneva, Switzerland.

Uribe, M. (2017). Infraestructuras de pazy estatalidad en Colombia. Revista Perfiles Latinoamericanos, 26(51), 167-189.

Valencia, G. (2012). Negociar la paz: una síntesis de la resolución negociada de los conflictos armados internos. Estudios Políticos, 40, 149-174.

Velázquez, E. (2007). Historia del paramilitarismo en Colombia. História (São Paulo), 26(1), 134-153.

Verdad Abierta. (18 de diciembre de 2014). Víctimas en La Habana: Ios que fuerony los que faltaron. Obtenido de sitio web de Verdad Abierta: https://verdadabierta.com/victimas-en-la-habana-los-que-fueron-y-los-que-faltaron/

Villarraga, A. (Comp.). (2013). Movimiento Ciudadano y Social por la Paz (Tomo IX, Biblioteca de la Paz. 1980 2013). Bogotá: Cente Nueva.

Zartman, W. (1991) Conflict and resolution: contest, cost and change. Annals of the American Academy of Political and Social Science, 518, 11-22. 